\title{
Severe Calorie Restriction Reduces Cardiometabolic Risk Factors and Protects Rat Hearts from Ischemia/Reperfusion Injury
}

\author{
Dirceu S. Melo ${ }^{1,2}$, Liliane V. Costa-Pereira ${ }^{1}$, Carina S. Santos ${ }^{1}$, Bruno F. Mendes ${ }^{1}$, \\ Karine B. Costa ${ }^{1}$, Cynthia Fernandes F. Santos ${ }^{2}$, Etel Rocha-Vieira ${ }^{1,2}$, \\ Flávio C. Magalhães ${ }^{1,3}$, Elizabethe A. Esteves ${ }^{1,3}$, Anderson J. Ferreira ${ }^{4}$, \\ Silvia Guatimosim ${ }^{1,5}$ and Marco F. Dias-Peixoto ${ }^{1,3 *}$ \\ 1 Programa Multicêntrico de Pós Graduação em Ciências Fisiológicas, Sociedade Brasileira de Fisiologia, São Paulo, Brasil, \\ ${ }^{2}$ Faculdade de Medicina, Campus JK, Universidade Federal dos Vales do Jequitinhonha e Mucuri, Diamantina, Brasil, \\ ${ }^{3}$ Faculdade de Ciências Biológicas e da Saúde, Universidade Federal dos Vales do Jequitinhonha e Mucuri, Diamantina, \\ Brasil, ${ }^{4}$ Departamento de Morfologia, Universidade Federal de Minas Gerais, Belo Horizonte, Brasil, ${ }^{5}$ Departamento de \\ Fisiologia e Biofísica, Universidade Federal de Minas Gerais, Belo Horizonte, Brasil
}

\section{OPEN ACCESS}

Edited by:

Elisabeth Lambert, BakerIDI Heart and Diabetes Institute,

Australia

Reviewed by:

Owen Woodman RMIT University, Australia James Todd Pearson, Monash University, Australia

${ }^{*}$ Correspondence: Marco F. Dias-Peixoto marcofabriufvim@gmail.com

Specialty section: This article was submitted to Integrative Physiology a section of the journal

Frontiers in Physiology

Received: 08 January 2016 Accepted: 04 March 2016

Published: 08 April 2016

Citation:

Melo DS, Costa-Pereira LV Santos CS, Mendes BF, Costa KB,

Santos CFF, Rocha-Vieira E, Magalhães FC, Esteves EA, Ferreira AJ, Guatimosim S and Dias-Peixoto MF (2016) Severe

Calorie Restriction Reduces Cardiometabolic Risk Factors and

Protects Rat Hearts from Ischemia/Reperfusion Injury. Front. Physiol. 7:106 doi: 10.3389/fphys.2016.00106
Background and Aims: Recent studies have proposed that if a severe caloric restriction (SCR) is initiated at the earliest period of postnatal life, it can lead to beneficial cardiac adaptations later on. We investigated the effects of SCR in Wistar rats from birth to adult age on risk factors for cardiac diseases (CD), as well as cardiac function, redox status, and HSP72 content in response to ischemia/reperfusion (I/R) injury.

Methods and Results: From birth to the age of 3 months, CR50 rats were fed 50\% of the food that the ad libitum group (AL) was fed. Food intake was assessed daily and body weight were assessed weekly. In the last week of the SCR protocol, systolic blood pressure and heart rate were measured and the double product index was calculated. Also, oral glucose and intraperitoneal insulin tolerance tests were performed. Thereafter, rats were decapitated, visceral fat was weighed, and blood and hearts were harvested for biochemical, functional, tissue redox status, and western blot analyzes. Compared to $\mathrm{AL}, \mathrm{CR} 50$ rats had reduced the main risk factors for $\mathrm{CD}$. Moreover, the FR50 rats showed increased cardiac function both at baseline conditions (45\% > AL rats) and during the post-ischemic period (60\% > AL rats) which may be explained by a decreased cardiac oxidative stress and increased HSP72 content.

Conclusion: SCR from birth to adult age reduced risk factors for CD, increased basal cardiac function and protected hearts from the $\mathrm{l} / \mathrm{R}$, possibly by a mechanism involving ROS.

Keywords: cardiac function, cardiometabolic risk factors, cardioprotection, severe calorie restriction, oxidative stress

\section{INTRODUCTION}

Cardiac diseases (CD) are the main leading cause of mortality worldwide accounting for up to $30 \%$ of all deaths (Go et al., 2014; Nichols et al., 2014). High-calorie plays a significant role in the development of $\mathrm{CD}$ by raising risk factors, such as dyslipidemia, high blood pressure, and hyperinsulinemia (Bornfeldt and Tabas, 2011). A great body of evidence has shown that limiting 
caloric intake is an effective non-pharmacological strategy to reduce cardiometabolic risk factors and to improve heart function delaying the onset of CD.

The cardioprotective effects of calorie restriction (CR) are well-documented for a long-term moderate CR (20-40\% reduction) (Han et al., 2012; Peart et al., 2012; Noyan et al., 2015). However, few studies have focused on the effects of a longterm severe CR (SCR) ( $\geq 40 \%$ ) on the heart, and the results are controversial. Some groups have reported positive effects of SCR on cardiac function under basal conditions (Han and Ren, 2010; Melo et al., 2013) and after cardiac insult (Yamagishi et al., 2010). However, other studies have found no significant effects (Long et al., 2002), or even undesirable effects (Okoshi et al., 2001; Sugizaki et al., 2009).

A recent meta-analysis conducted by Han and Ren (2010), showed that the effects of CR are strongly associated with age, being positive when CR is started at earliest ages. In this context, the use of a long-term SCR initiated since the postnatal period would lead to a greater reduction in the metabolism later in life, forcing the heart to increase its contractile efficiency due to a reduced energy availability.

In our previous study, we demonstrated that young adult rats (90-day old) submitted to a 50\% CR since the first weeks of age presented increased basal heart function, increased cardiomyocyte density and number as well as increased levels of phosphorylated AKT (Melo et al., 2013). Based on this knowledge, we hypothesized that SCR started at the earliest period of the rodents' postnatal life and maintained until adulthood might lead to beneficial effects. The purpose of this study was to investigate: (i) if SCR rats present improvement on cardiometabolic risk factors and (ii) if SCR protects hearts against ischemia-reperfusion (I/R). Additionally, we evaluated the cardiac redox status and heat shock protein 72 (HSP72) expression as possible protective mechanisms in post-ischemic SCR-hearts.

\section{METHODS}

Experimental protocols were performed in accordance with the Guide for the Care and Use of Laboratory Animals published by the US National Institutes of Health (NIH Publication, 1996). The experimental protocols were approved by Ethics Committee on Animal Use/Federal University of Jequitinhonha and Mucuri Valleys, Diamantina, MG, Brazil, protocol \#04/2015.

\section{Animals and Caloric Restriction Protocol}

Female pregnant Wistar rats $(n=8)$, approximately 90 days of age, were housed in individual cages and maintained in a room with controlled temperature $\left(22 \pm 2{ }^{\circ} \mathrm{C}\right)$ and a $12 \mathrm{~h}$ light$12 \mathrm{~h}$ dark cycle, with free access to food and water. After they gave birth, half of the mothers $(n=4)$ were assigned to ad libitum-fed group, and the other half $(n=4)$ was assigned to the calorie-restricted group. Both groups had free access to water. In the mothers assigned to the calorie-restricted group, the amount of food provided on a daily basis was equivalent to $50 \%$ of the amount consumed by the mothers in the ad libitumfed group, and each mother suckled 8 newborn rats for 21 days.
After weaning, rats were housed in individual cages and received the same treatment as their mothers up to the age of 90 days. The weaned rats were divided into rats fed ad libitum (AL rats; $n=9$ ) and rats subjected to long-term SCR (CR50 rats; $n=11)$.

\section{Food Intake, Weight Gain, and Feed Efficiency Ratio}

The food intake of the AL group was evaluated daily and this value was used to calculate the offer to the CR50 group. Body weight was monitored weekly. Feed efficiency ratio was measured from the ratio between the total weight gain and overall food intake.

\section{Systolic Blood Pressure, Heart Rate, and Double Product Ratio}

The rats were previously familiarized with the procedures for tail-cuff plethysmography for 5 days (MLT1020PPG IR Plethysmograph, ADInstruments). Tail systolic blood pressure and heart rate were measured at the last week prior to the end of the experiment. Additionally, we calculated the double product index using systolic blood pressure and heart rate values, an indicative of cardiac work (Schutte et al., 2013).

\section{Basal Metabolic Rate}

After an overnight fast $(12 \mathrm{~h})$, the resting metabolic rate was assessed by the average oxygen consumption $\left(\mathrm{VO}_{2}\right)$ and carbon dioxide production $\left(\mathrm{VCO}_{2}\right)$ within a period of $60 \mathrm{~min}$. The measurements were taken by a computer-monitored indirect calorimeter (Oxyleptro, Harvard Apparatus, Spain) coupled to a metabolic chamber (air flow $=1.0 / \mathrm{min}$ ), which accommodated the rats. The calorimetric parameters were measured using a respiratory-based software program (software Metaoxy, Harvard Apparatus, Spain).

\section{Oral Glucose Tolerance Test (OGTT)}

Immediately after the basal metabolic rate measurement, glucose was administered by gavage ( $2 \mathrm{~g} / \mathrm{kg}$ body weight; $50 \%$ solution). Blood glucose levels were determined by small clipping of the rat tail, immediately before $(0 \mathrm{~min})$ the glucose challenge, as well as at 30,60, and 120 min thereafter. Blood glucose levels were determined using an ACCU-CHEK (Advantage Glucose Analyzer, Roche Diagnostics Corporation, IN, USA).

\section{Intraperitoneal Insulin Tolerance Test (IpITT)}

Forty-eight hours after the OGTT, the animals were fasted for $8 \mathrm{~h}$, then an intraperitoneal injection of insulin (1 IU/kg body weight) was administered. Blood glucose levels were determined following the same OGTT protocol.

\section{Ex vivo Analysis and Langendorff Preparation}

The animals were anesthesized with ketamine $(10 \mathrm{mg} / \mathrm{kg})$ and xylazine $(5 \mathrm{mg} / \mathrm{kg})$ and decapitated $10-15 \mathrm{~min}$ after an intraperitoneal injection of $400 \mathrm{IU}$ heparin. The hearts were perfused in a Langendorff apparatus (ML785B2, ADInstruments) and left ventricular pressure $( \pm \mathrm{dP} / \mathrm{dt})$ was continuously 
recorded according to the Langendorff technique. Briefly, the thorax was opened and the heart was carefully dissected and rapidly cannulated and retrogradely perfused with Krebs-Ringer solution (in mmol. $\mathrm{L}^{-1}$ : $\mathrm{NaCl}, 118.40 ; \mathrm{KCl}, 4.70 ; \mathrm{KH} 2 \mathrm{PO} 4,1.17$; $\mathrm{MgSO} 4,1.17$; $\mathrm{CaCl} 2$, 2.50; glucose, 11.65; and $\mathrm{NaHCO} 3,26.30)$ at $37 \pm 1^{\circ} \mathrm{C}$, with constant pressure $(65 \mathrm{~mm} \mathrm{Hg})$ and oxygenation (5\% CO2 and 95\% O2). A water-filled latex balloon coupled to a pressure transducer (MLT0380, ADInstruments) was inserted into the left ventricular cavity via the left auricle to record pressure. The rate of pressure development $( \pm \mathrm{dP} / \mathrm{dt})$ was obtained by calculating derivatives from the pressure variation recordings, using the Labchart8 software. After $20 \mathrm{~min}$ of stabilization in the perfusion system, the hearts were evaluated at baseline cardiac function for $20 \mathrm{~min}$ and then subjected to global ischemia (total blockage of the Krebs Ringer solution flow) for $20 \mathrm{~min}$. After induction of ischemia, the hearts were reperfused for an additional $20 \mathrm{~min}$ to evaluate the post-ischemic cardiac function. All the $\pm \mathrm{dP} / \mathrm{dt}$ measurements were normalized to heart weight.

\section{Organ Weights and Adiposity Index}

Liver, kidney, spleen, epididymal, and retroperitoneal fat was removed and weighted. The adiposity index was calculated as following: [epididymal fat + retroperitoneal fat/(body weightsum of fat pads)] * 100 as described by Boustany et al. (2004).

\section{Blood Lipids Analyses}

Blood was centrifuged to obtain plasma, and then aliquoted in eppendorf tubes and kept at $-80^{\circ} \mathrm{C}$ until analyses. Total plasma cholesterol (CHOL), high-density lipoprotein cholesterol (HDL-C) and triglyceride (TG) levels were determined using commercial kits (LabTest ${ }^{\circledR}$ ), according to the specifications of the manufacturer and using a semi-automatic biochemical analyzer (PW-3000, PIOWAY, China). The low-density lipoprotein cholesterol (LDL-C) level was also estimated by using the Friedewald equation (Friedewald et al., 1972) and very low density lipoprotein (VLDL-C) was calculated from the triglyceride values and atherogenic index as described by Nwagha et al. (2010).

\section{Cardiac Redox Status}

Left cardiac ventricle samples were weighed, immersed in phosphate-buffered saline (PBS), $\mathrm{pH} 7.2$, extensively washed to remove blood and stored at $-80^{\circ} \mathrm{C}$ until the time of assay. At the time of assay, samples were then homogenized ( $\mathrm{T} 20$ basic ULTRA-TURRAX; IKA Labortechnik, China) for $3 \mathrm{~min}$ at 0 $4^{\circ} \mathrm{C}$. After this, the homogenate was centrifuged for $10 \mathrm{~min}$ at $10,000 \mathrm{xg}$ (Jouan BR4i, Thermo Fischer Scientific, USA), and the supernatant was used for the biochemical assays described below. Protein concentration for all assays was determined according to Bradford (1976) using bovine serum albumin (BSA, Sigma, USA) as standard.

The assay to determine SOD activity (EC 1.15.1.1) was performed according to Marklund and Marklund (1974) with some modifications. In brief, sample of tissue homogenate was added in $50 \mathrm{mM}$ sodium phosphate buffer $\left(1 \mathrm{~mL}, \mathrm{pH} 7.8,37^{\circ} \mathrm{C}\right)$ containing $1 \mathrm{mM}$ diethylenetriamine pentaacetic acid (DTPA,
Sigma, USA). The reaction was started by adding $0.2 \mathrm{mM}$ pyrogallol (Sigma, USA), and the samples were heated to $37^{\circ} \mathrm{C}$ for $3 \mathrm{~min}$. The absorbance was determined at $420 \mathrm{~nm}$ (Shimadzu UV 2450, Shimadzu Corporation, Japan). SOD activity was calculated as units per milligram of protein, and one unit of enzyme was considered as being the amount that caused inhibition of pyrogallol autoxidation by $50 \%$. Measurements were performed in triplicate.

Catalase (EC 1.11.1.6) activity was measured in the supernatants as described by Nelson and Kiesow (1972). Briefly, $0.04 \mathrm{ml}$ of $\mathrm{H} 2 \mathrm{O} 2$ was added as substrate to $0.06 \mathrm{ml}$ of tissue homogenate and $2 \mathrm{ml}$ of potassium phosphate buffer $(50 \mathrm{mM}, \mathrm{pH} 7.0)$ to give a final $\mathrm{H} 2 \mathrm{O} 2$ concentration of $6 \mathrm{mM}$, and the reaction proceeded for $1 \mathrm{~min}$ at room temperature. Decomposition of $\mathrm{H} 2 \mathrm{O} 2$ by catalase was noted by the change in absorbance at $240 \mathrm{~nm}$ (DE) (Shimadzu UV 2450, Shimadzu Corporation, Japan). Experiments were performed in triplicate. Catalase activity was expressed by millimoles of $\mathrm{H} 2 \mathrm{O} 2$ decomposed per minute per milligram of protein $(\mathrm{E} \times$ $\mathrm{min}^{-1} \times \mathrm{mg}^{-1}$ protein). This procedure avoids the possible interference associated with glutathione peroxidase activity since the necessary cofactors are not present in the reaction media.

As an index of lipid peroxidation, we used the formation of thiobarbituric acid-reactive substance (TBARS) during an acid-heating reaction (Ohkawa et al., 1979). Briefly, $0.4 \mathrm{ml}$ of tissue homogenate was added to $0.2 \mathrm{ml}$ of $8.1 \%$ sodium dodecyl sulfate, $0.5 \mathrm{ml}$ of acetic acid (2.5 M, pH 3.4), and $1 \mathrm{ml}$ of $0.8 \%$ thiobarbituric acid (Sigma, USA), and they were then heated in a boiling water bath $\left(90^{\circ} \mathrm{C}\right)$ for $60 \mathrm{~min}$. Samples then were centrifuged for $5 \mathrm{~min}$ at 50,000 $\mathrm{g}$ (Jouan BR4i, Thermo Fischer Scientific, USA). TBARS were determined by the absorbance at $532 \mathrm{~nm}$ (Shimadzu UV 2450, Shimadzu Corporation, Japan), compared with a standard curve constructed with known concentrations of malondialdehyde (1,1,3,3-tetramethoxy- propane) (Sigma, USA) as an external standard. The amount of malondialdehyde (MDA) produced was interpreted as the TBARS levels and indicates the degree of oxidative stress. The results are expressed as MDA equivalents per milligram of protein. Measurements were performed in triplicates.

\section{Western Blot}

Total protein content of left cardiac ventricles was quantified with the Bradford protein assay (Bradford, 1976). Protein $(50 \mu \mathrm{g})$ was loaded onto a $10 \%$ polyacrylamide gel for electrophoresis. After electrophoresis, proteins were transferred to a PVDF membrane, blocked with a 5\% nonfat milk solution, and washed in phosphate-buffered saline, containing $0.1 \%$ Tween 20. Membranes were incubated overnight at $4{ }^{\circ} \mathrm{C}$ with the following primary antibodies: Hsp72 (1:5000 dilution-Enzo Life Sciences) and glyceraldehyde 3-phosphate dehydrogenase (GAPDH, 1:5000 dilution-Cell Signaling) Thereafter, a monoclonal anti-rabbit or anti-mouse secondary antibody conjugated with peroxidase (1:7500 dilution, Cell Signaling) were used. Immunodetection was carried out using enhanced chemiluminescence (Amersham Biosciences), and protein levels were expressed as a ratio of optical densities. 


\section{Statistical Analysis}

All data are expressed as means \pm standard deviation. Statistical significance was estimated using Student's $t$ test or ANOVA, followed by Tukey's post-hoc test (GraphPad Prism 4.0). The level of significance was set at $p<0.05$.

\section{RESULTS}

The characteristics of the groups are presented in Table 1. As expected, CR50 rats had a 40\% lower final body weight compared to AL rats. Additionally, feed efficiency ratio was $18 \%$ higher in CR50 rats, which may be explained by a reduced basal oxygen consumption of these animals. Also, most organ weights were reduced in CR50 rats. Interestingly, although heart weight of CR50 was lower, we found similar heart/body weight ratio in these rats when compared to AL rats.

Next, we evaluated the effects of $50 \%$ CR on key risk factors for developing CD (Table 2). We found that most of these cardiometabolic risk factors were reduced in CR50 rats. Specifically, when compared to AL, CR50 rats had reduction in adiposity index and visceral fat weight, improvement in plasma lipid profile, as shown by increased HDL cholesterol, decreased LDL and atherogenic index. Also, CR50 rats had an improvement in glucose tolerance and insulin response, which indicates higher insulin sensitivity. Cardiovascular parameters also indicate protective effects of CR. CR50 rats had lower systolic blood pressure and cardiac double product index compared to $\mathrm{AL}$ rats.

To address if reductions of cardiometabolic risk factors in CR50 rats were followed by an improvement of direct cardiac function, we performed Langendorff analysis (Figure 1). Confirming our previous study Melo et al. (2013), CR50 rats showed increased basal cardiac function as evidenced by increased contractility $(+\mathrm{dP} / \mathrm{dt})[\mathrm{AL}(n=9): 1310 \pm 96$, CR50 ( $n=11): 2448 \pm 177 \mathrm{mmHg} / \mathrm{s}-1 / \mathrm{g}-1$, Figure 1A] and relaxation $(-\mathrm{dP} / \mathrm{dt})[\mathrm{AL}(n=9): 660 \pm 56$, CR50 $(n=11)$ : $1310 \pm 125 \mathrm{mmHg} / \mathrm{s}-1 / \mathrm{g}-1$. Figure 1B] indexes without change of intrinsic heart rate [AL $(n=9): 220 \pm 16$, CR50 $(n=11)$ : $231 \pm 13 \mathrm{bpm}$, Figure 1C]. In order to investigate if the CR would

TABLE 1 | General characteristics of Ad Libitum (AL) and 50\% SCR (CR50) rats.

\begin{tabular}{|c|c|c|}
\hline & $\begin{array}{c}\mathrm{AL} \\
(n=9)\end{array}$ & $\begin{array}{c}\text { CR50 } \\
(n=11)\end{array}$ \\
\hline Final body weight (g) & $288.2 \pm 10.0$ & $167.1 \pm 3.5^{*}$ \\
\hline Final food intake (g) & $1489 \pm 38$ & $746 \pm 19^{\star}$ \\
\hline Feed efficiency ratio (\%) & $19.4 \pm 0.6$ & $23.0 \pm 0.2^{*}$ \\
\hline VO2 (ml/min/ $\left.\mathrm{Kg}^{\wedge 0.75}\right)$ & $22.5 \pm 0.5$ & $20.5 \pm 0.7^{\star}$ \\
\hline Heart (g) & $1.2 \pm 0,1$ & $0.7 \pm 0.1^{\star}$ \\
\hline Heart/Body (mg/g) & $4.4 \pm 0.2$ & $4.2 \pm 0.1$ \\
\hline Liver $(\mathrm{g})$ & $10.7 \pm 1.7$ & $5.9 \pm 0.4^{*}$ \\
\hline Kidneys (g) & $1.1 \pm 0.1$ & $0.6 \pm 0.1^{*}$ \\
\hline Spleen (g) & $0.8 \pm 0.1$ & $0.5 \pm 0.1^{*}$ \\
\hline
\end{tabular}

Data are presented as mean $\pm S D$. ${ }^{*} P<0.05$. AL vs. CR50. T student test. also have cardioprotective effects in response to a specific stress condition, we subjected the hearts to $20 \mathrm{~min}$ of global ischemia followed by an equal period of reperfusion. Compared with AL, CR50 hearts had higher cardiac function at the post-ischemic period as shown by higher $+\mathrm{dP} / \mathrm{dt}[\mathrm{AL}(n=8): 384 \pm 55$, CR50 $(n=9): 1001 \pm 132 \mathrm{mmHg} / \mathrm{s}-1 / \mathrm{g}-1$, Figure $1 \mathbf{A}]$ and $-\mathrm{dP} / \mathrm{dt}$ [AL $(n=8): 236 \pm 34$, CR50 $(n=9): 585 \pm 33 \mathrm{mmHg} / \mathrm{s}-$ $1 / \mathrm{g}-1$. Figure $1 \mathrm{~B}]$ with no significant difference in heart rate [AL $(n=8): 100 \pm 14$, CR50 $(n=9): 131 \pm 57 \mathrm{bpm}$, Figure 1C] Of note, despite an expected reduction in cardiac function after global ischemic challenge in both groups, the $\pm \mathrm{dP} / \mathrm{dt}$ indexes in post-ischemic CR50 hearts were similar to that seen in AL hearts at baseline levels.

In order to further understand the mechanisms involved in the cardioprotective effects of our CR protocol in I/R injury, we assessed cardiac oxidative stress by measuring lipid peroxidation, catalase and superoxide dismutase activities in post-ischemic hearts. As shown in Figure 2, post-ischemic CR50 hearts had lower levels of lipid peroxidation (AL: $2.46 \pm 0.14$, CR50: $1.56 \pm 0.13 \mathrm{nmolMDA} / \mathrm{mg}$ protein, Figure 2A), as well as higher activities of SOD [AL $(n=8): 6.3 \pm 0.9$, CR50 $(n=9): 16.8 \pm$ $3.4 \mathrm{U} / \mathrm{mg}$ protein, Figure 2B], and CAT [AL $(n=8): 0.6 \pm$ 0.05 , CR50 $(n=9): 1.4 \pm 0.2 \Delta \mathrm{E} / \mathrm{min} / \mathrm{mg}$ protein, Figure $2 \mathrm{C}]$ compared with post-ischemic AL hearts. Additionally, HSP72 content was higher in post-ischemic CR50 hearts (AL: $0.65 \pm$ 0.02, CR50: $0.82 \pm 0.09$ a.u., Figure 2D).

\section{DISCUSSION}

In the current study, we evaluated the cardioprotective effects of SCR since birth to the age of 3 months in Wistar rats. First, we found that CR50 rats presented a reduction in main cardiometabolic risk factors, as shown by (i) diminished adiposity index and visceral fat weight; (ii) improvement of the

TABLE 2 | Severe calorie restriction reduces cardiometabolic risk factors. Ad Libitum (AL) and 50\% SCR (CR50) rats.

\begin{tabular}{|c|c|c|}
\hline & $\begin{array}{c}\text { AL } \\
(n=9)\end{array}$ & $\begin{array}{c}\text { CR50 } \\
(n=11)\end{array}$ \\
\hline Visceral fat (g) & $11.3 \pm 1.9$ & $2.5 \pm 0.2^{*}$ \\
\hline Adiposity index (\%) & $3.9 \pm 0.3$ & $1.5 \pm 0.1^{*}$ \\
\hline Triglycerides (mg/dL) & $111.1 \pm 5.6$ & $106.4 \pm 4.2$ \\
\hline Cholesterol (mg/dL) & $61.5 \pm 3.1$ & $61.4 \pm 2.7$ \\
\hline HDL_cholesterol (mg/dL) & $20.2 \pm 0.9$ & $23.4 \pm 0.8^{\star}$ \\
\hline LDL - cholesterol (mg/dL) & $24.0 \pm 4.0$ & $14.3 \pm 0.8^{*}$ \\
\hline VLDL_cholesterol (mg/dL) & $23.8 \pm 1.8$ & $21.2 \pm 0.8$ \\
\hline Atherogenic index (mg/dL) & $3.0 \pm 0.1$ & $2.4 \pm 0.1^{\star}$ \\
\hline Basal glucose $(\mathrm{mg} / \mathrm{dL})$ & $97.8 \pm 3.0$ & $94.3 \pm 1.0$ \\
\hline Area under curve OGTT (mg/dL/min) & $14410 \pm 311$ & $13280 \pm 265^{*}$ \\
\hline Area under curve ITT (mg/dL/min) & $269.9 \pm 10.3$ & $208.7 \pm 9.4^{*}$ \\
\hline Systolic blood pressure $(\mathrm{mmHg})$ & $134.9 \pm 3.8$ & $123.2 \pm 2.6^{*}$ \\
\hline Heart rate in vivo (bpm) & $402 \pm 11$ & $382 \pm 7$ \\
\hline Double product index (mmHg $\left.{ }^{\star} \mathrm{bpm}\right)$ & $55490 \pm 1516$ & $46640 \pm 1655^{\star}$ \\
\hline
\end{tabular}

"Data are presented as mean $\pm S D$. ${ }^{*} P<0.05$ AL vs. CR50. T student test. 


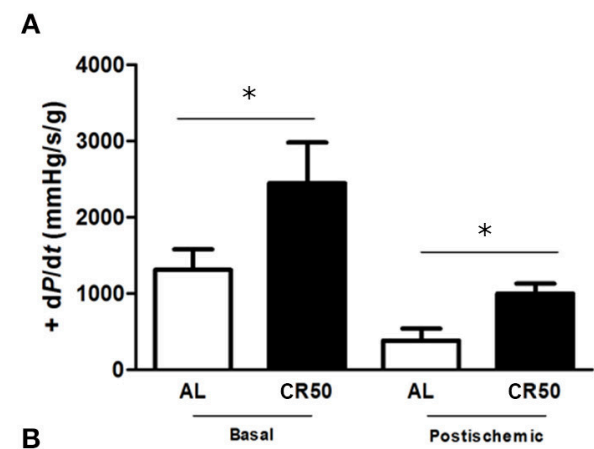

B

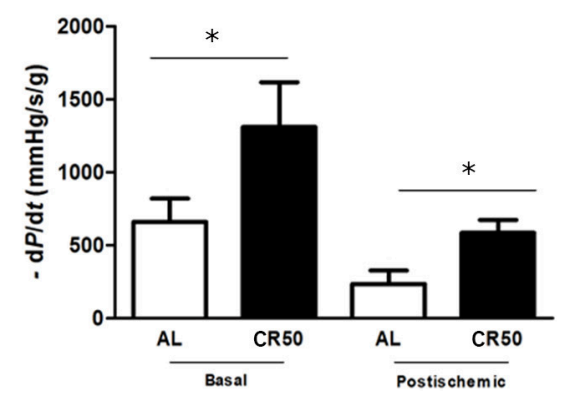

C

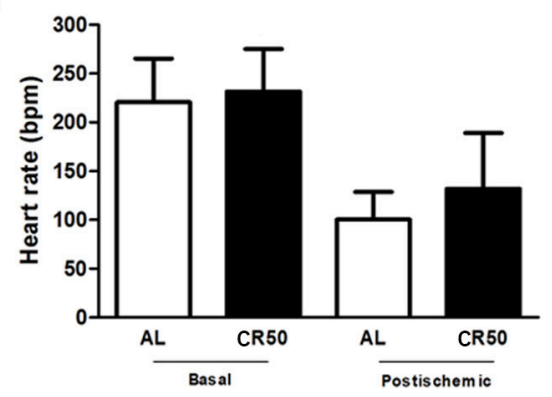

FIGURE 1 | Severe calorie restriction improves basal and post-ischemic cardiac function. Ad Libitum (AL) and 50\% Calorie Restricted (CR50) rats. Contractility index $(+\mathrm{dP} / \mathrm{dt}) \mathbf{( A )}$, relaxation index $(-\mathrm{dP} / \mathrm{dt})$ (B) and heart rate (C) of Ad Libitum (AL) and 50\% Calorie Restricted (CR50) rats. Data are presented as mean $\pm \mathrm{SD}$. ${ }^{\star} P<0.05$. Anova one-way followed by Tukey post-hoc test.

plasma lipid profile and atherogenic index; (iii) improvement of the glucose tolerance and insulin response, indicating a higher insulin sensitivity; and (iv) reduced systolic blood pressure, cardiac double product index and basal metabolic rate. Moreover, CR50 rats showed increased cardiac function both at baseline levels $(45 \%>\mathrm{AL}$ rats) and during postischemic period $(60 \%>\mathrm{AL}$ rats) which may be explained by a decreased cardiac oxidative stress and increased HSP72 content.

The effects of SCR on cardiac function have been poorly investigated with some controversial results. Although most studies supported the notion that SCR induces positive effects (Broderick et al., 2002; Peron et al., 2005; Han and Ren, 2010; Yamagishi et al., 2010; Melo et al., 2013), some groups demonstrated that SCR has negative effects (Okoshi et al., 2001; Sugizaki et al., 2009; de Tomasi et al., 2009) on the heart. The main explanation for these discrepancies is related to the different experimental conditions. Of note, the period of life in which the CR is initiated is thought to be critical in determining its effects (Han and Ren, 2010). Recently, we found that SCR imposed since birth to the age of 3 months had positive effects on basal cardiac function of Wistar rats (Melo et al., 2013).

Based on our previous data (Melo et al., 2013), two questions were left open regarding the apparent beneficial effects of our CR protocol on heart function. First, we speculated that the increased basal heart function in CR50 rats could be a transitory adaptive change that occurs, for example, in response to cardiometabolic disorders, such as increased blood pressure (Young, 2010). In this study, we discarded this possibility, since the increased basal heart function of CR50 rats was followed by marked positive effects on cardiometabolic parameters. CR50 rats also had a significantly lower basal metabolic rate compared with AL rats. These improvements are in keeping with previous results observed after a traditional moderate long term CR (Park et al., 2005; Niemann et al., 2010) and they have been linked to an adaptative reduction in energy expenditure. The decreased basal metabolic rate has been postulated as one of the mechanisms by which CR exerts cardioprotection, probably through a decrease in ROS generation and a subsequent organ damage reduction (Hulbert, 2010; Kawahara et al., 2014).

The other question left unanswered in our previous study was if, despite the increased basal response, CR50 heart function would be more susceptible to a specific stress. To that end we performed I/R experiments. In fact, CR50 rats not only showed significantly increased heart function at basal levels (confirming our previous findings), but also during the post-ischemic period compared to AL hearts. The post-ischemic function of CR50 hearts actually was similar to the basal levels of AL hearts and 60\% higher than the post-ischemic levels of AL hearts. These findings are supported by other studies showing that a long-term SCR protects heart function during the post-ischemic period in adult (Broderick et al., 2002) and senescent (Abete et al., 2002) rats. At baseline levels, Broderick et al. (2002) did not find differences in cardiac function between AL 11-month old rats and age-matched rats restricted by $45 \%$ for 32 weeks. However, the post-ischemic cardiac function of CR rats was $28 \%$ higher than in AL rats. Abete et al. (2002) also did not observe differences at baseline levels; Yet at the post-ischemic period, 24-month old rats restricted by $40 \%$ for 12 months had $40 \%$ higher cardiac function than AL agematched rats. In the present study, SCR rats had not only a higher cardiac function at the post-ischemic period (60\% higher than $\mathrm{AL}$ rats) but also at baseline levels (45\% higher than $\mathrm{AL}$ rats). Our results support data obtained from Han and Ren (2010), which suggest that the sooner the CR is started, the greater are its benefits. Thus, we believe that hearts of adult rats, which had started SCR at the first postnatal weeks, may adapt to a condition of reduced energy availability, thereby resulting in an increased cardiac efficiency.

A possible mechanism involved in these benefits, especially the preservation of the cardiac function at the post-ischemic period, may be a lower increase in ROS generation in response to an ischemic insult. Low levels of ROS regulate a variety of key mechanisms involved in the homeostasis of heart function 
A

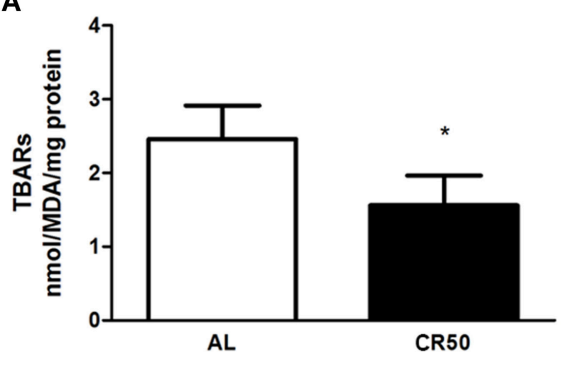

C

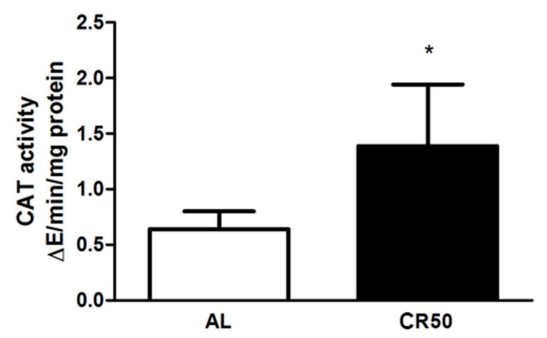

B

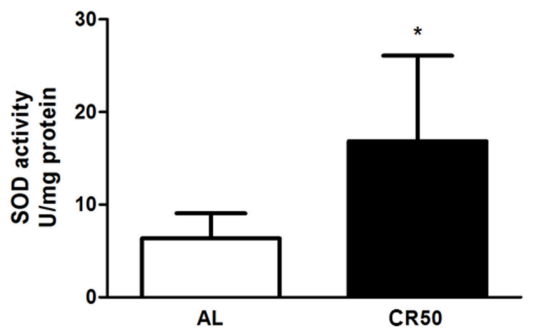

$A L$

CR50

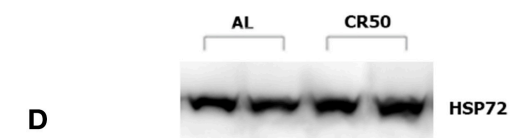

D

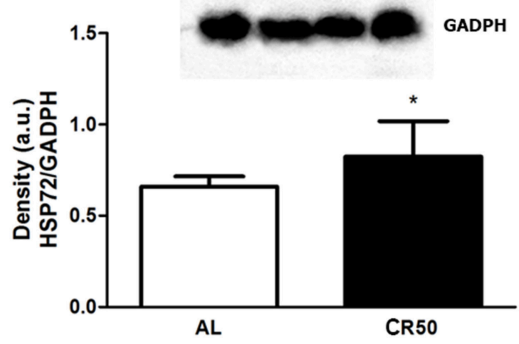

FIGURE 2 | Severe calorie restriction reduces oxidative stress in post-ischemic hearts. Ad Libitum (AL) and 50\% Calorie Restricted (CR50) rats. (A) TBARs levels, (B) SOD activity, (C) CAT activity, and (D) expression levels of HSP72 of Ad Libitum (AL) and 50\% Calorie Restricted (CR50) rats. Data are presented as mean $\pm \mathrm{SD}$. ${ }^{*} P<0.05 \mathrm{AL}$ vs. CR50 rats. $T$ student test.

(Hancock et al., 2001; Cadenas, 2004). During I/R injuries ROS is generated at high levels which is associated with cardiac dysfunction (Chen and Zweier, 2014; Silachev et al., 2014). The increase in lipid peroxidation, especially within the sarcoplasmic reticulum, is thought to be a determinant for impaired calcium handling and contractile dysfunction during I/R events (Dhalla et al., 2000; Kaplan et al., 2003). Some studies have proposed that a long-term CR leads to increased tolerance against I/R insult by reducing ROS generation (Shinmura et al., 2011; Walsh et al., 2014) and/or increasing antioxidant activity during the cardiac post-ischemic period (Chandrasekar et al., 2001; Walsh et al., 2014). Therefore, we also attributed the improved cardiac function of CR50 rats at the post-ischemic period to the higher SOD and CAT activities, which might be responsible for the lower levels of lipid peroxidation compared to post-ischemic AL hearts.

The HSP family, especially HSP72, is believed to provide myocardial protection against increased ROS generation during I/R events (Suzuki et al., 2002; Powers et al., 2008). HSP72 is strongly activated during I/R insults and triggers a counter-regulatory action against cellular oxidative damage by modulating the SOD (Suzuki et al., 2002) and CAT (Colotti et al., 2005) activities. To our knowledge, there are no studies evaluating the levels of HSP72 expression in response to $\mathrm{I} / \mathrm{R}$ injury in SCR rats. Here, we showed that SCR hearts subjected to $\mathrm{I} / \mathrm{R}$ insult presented higher HSP72 levels which may cause an increase in the antioxidant response preserving cardiac function. However, a complete characterization of the mechanisms underlying these cardioprotective effects was beyond the scope of the present study. Thus, future studies should evaluate if cardioprotective effects of SCR since birth would be observed in other situations. For example, if this protective effect would be lost after a period of refeeding or even if it would be maintained later in life or in pathological conditions.

In conclusion, our findings revealed that SCR from birth to adult age reduces the main cardiometabolic risk factors and directly improves cardiac function at baseline and after an I/R insult. This latter effect may be a result of a decrease in ROS damage through increased antioxidant responses which could be triggered by an increase in HSP72 content.

\section{AUTHOR CONTRIBUTIONS}

Conceived and designed the experiments: DM, MD; performed the experiments: DM, LC, CS, BM, and KC; analyzed the data: DM; contributed reagents/materials/analysis tools: CS, EV, FM, EE; wrote the paper: DM, MD, AF, and SG.

\section{ACKNOWLEDGMENTS}

This study was partially supported by the Brazilian agencies FAPEMIG (Fundação de Amparo à Pesquisa do Estado de Minas Gerais, APQ-00075-15), CAPES (Coordenação de Aperfeiçoamento de Pessoal de Nível Superior) and $\mathrm{CNPq}$ (Conselho Nacional de Desenvolvimento Científico e Tecnológico, 479807/2013-2). 


\section{REFERENCES}

Abete, P., Testa, G., Ferrara, N., De Santis, D., Capaccio, P., Viati, L., et al. (2002). Cardioprotective effect of ischemic preconditioning is preserved in foodrestricted senescent rats. Am. J. Physiol. Heart Circ. Physiol. 282, 1978-1987. doi: 10.1152/ajpheart.00929.2001

Bornfeldt, K. E., and Tabas, I. (2011). Insulin resistance, hyperglycemia, and atherosclerosis. Cell Metab. 14, 575-585. doi: 10.1016/j.cmet.2011.07.015

Boustany, C. M., Bharadwaj, K., Daugherty, A., Brown, D. R., Randall, D. C., and Cassis, L. A. (2004). Activation of the systemic and adipose renin-angiotensin system in rats with diet-induced obesity and hypertension. Am. J. Physiol. Regul. Integr. Comp. Physiol. 287, 943-949. doi: 10.1152/ajpregu.00265.2004

Bradford, M. M. (1976). A rapid and sensitive method for the quantitation of microgram quantities of protein utilizing the principle of protein-dye binding. Anal. Biochem. 72, 248-254. doi: 10.1016/0003-2697(76)90527-3

Broderick, T., Belke, T., and Driedzic, W. (2002). Effects of chronic caloric restriction on mitochondrial respiration in the ischemic reperfused rat heart. Mol. Cell. Biochem. 233, 119-125. doi: 10.1023/A:1015506327849

Cadenas, E. (2004). Mitochondrial free radical production and cell signaling. Mol. Aspects Med. 25, 17-26. doi: 10.1016/j.mam.2004.02.005

Chandrasekar, B., Nelson, J. F., Colston, J. T., and Freeman, G. L. (2001). Calorie restriction attenuates inflammatory responses to myocardial ischemiareperfusion injury. Am. J. Physiol. Heart Circ. Physiol. 280, 2094-2102. Available online at: http://ajpheart.physiology.org/content/280/5/H2094. article-info

Chen, Y.-R., and Zweier, J. L. (2014). Cardiac mitochondria and reactive oxygen species generation. Circ. Res. 114, 524-537. doi: 10.1161/CIRCRESAHA.114.300559

Colotti, C., Cavallini, G., Vitale, R., Donati, A., Maltinti, M., Del Ry, S., et al. (2005). Effects of aging and anti-aging caloric restrictions on carbonyl and heat shock protein levels and expression. Biogerontology 6, 397-406. doi: 10.1007/s10522-005-4906-Z

de Tomasi, L. C., Bruno, A., Sugizaki, M. M., Lima-Leopoldo, A. P., Nascimento, A. F., Júnior, S. A. D. O., et al. (2009). Food restriction promotes down regulation of myocardial L-type Ca2+ channels. Can. J. Physiol. Pharmacol. 87, 426-431. doi: 10.1139/Y09-025

Dhalla, N. S., Elmoselhi, A. B., Hata, T., and Makino, N. (2000). Status of myocardial antioxidants in ischemia-reperfusion injury. Cardiovasc. Res. 47, 446-456. doi: 10.1016/S0008-6363(00)00078-X

Friedewald, W. T., Robert I. L., and Donald S. F. (1972). Estimation of the concentration of low-density lipoprotein cholesterol in plasma, without use of the preparative ultracentrifuge. Clin. Chem. 18, 499-502.

Go, A. S., Mozaffarian, D., Roger, V. L., Benjamin, E. J., Berry, J. D., Blaha, M. J., et al. (2014). Executive summary: heart disease and stroke statistics -2014 update: a report from the american heart association. Circulation 129, 399-410. doi: 10.1161/01.cir.0000442015.53336.12

Han, X., and Ren, J. (2010). Caloric restriction and heart function: is there a sensible link? Acta Pharmacol. Sin. 31, 1111-1117. doi: 10.1038/aps.2010.146

Han, X., Turdi, S., Hu, N., Guo, R., Zhang, Y., and Ren, J. (2012). Influence of long-term caloric restriction on myocardial and cardiomyocyte contractile function and autophagy in mice. J. Nutr. Biochem. 23, 1592-1599. doi: 10.1016/j.jnutbio.2011.11.002

Hancock, J. T., Desikan, R., and Neill, S. J. (2001). Role of reactive oxygen species in cell signalling pathways. Biochem. Soc. Trans. 29, 345-349. doi: $10.1042 /$ bst0290345

Hulbert, A. J. (2010). Metabolism and longevity: is there a role for membrane fatty acids? Integr. Comp. Biol. 50, 808-817. doi: 10.1093/icb/icq007

Kaplan, P., Babusikova, E., Lehotsky, J., and Dobrota, D. (2003). Free radical-induced protein modification and inhibition of Ca2+-ATPase of cardiac sarcoplasmic reticulum. Mol. Cell. Biochem. 248, 41-47. doi: 10.1023/A:1024145212616

Kawahara, E. I., Maués, N., dos Santos, K. C., Barbanera, P. O., Braga, C. P., and Fernandes, A. (2014). Energy restriction and impact on indirect calorimetry and oxidative stress in cardiac tissue in rat. Indian J. Biochem. Biophys. 51, $365-371$.

Long, P., Nguyen, Q., Thurow, C., and Broderick, T. L. (2002). Caloric restriction restores the cardioprotective effect of preconditioning in the rat heart. Mech. Ageing Dev. 123, 1411-1413. doi: 10.1016/S0047-6374(02)00068-4

Marklund, S., and Marklund, G. (1974). Involvement of the superoxide anion radical in the autoxidation of pyrogallol and a convenient assay for superoxide dismutase. Euro. J. Biochem. 47, 469-474. doi: 10.1111/j.14321033.1974.tb03714.x

Melo, D. S., Riul, T. R., Esteves, E. A., Moraes, P. L., Ferreira, F. O., Gavioli, M., et al. (2013). Effects of severe caloric restriction from birth on the hearts of adult rats. Appl. Physiol. Nutr. Metab. 38, 879-885. doi: 10.1139/apnm-2012-0387

Nelson, D. P., and Kiesow, L. A. (1972). Enthalpy of decomposition of hydrogen peroxide by catalase at $25^{\circ} \mathrm{C}$ (with molar extinction coefficients of $\mathrm{H} 2 \mathrm{O} 2$ solutions in the UV). Anal. Biochem. 49, 474-478. doi: 10.1016/00032697(72)90451-4

Nichols, M., Townsend, N., Scarborough, P., and Rayner, M. (2014). Cardiovascular disease in Europe 2014: epidemiological update. Eur. Heart J. 35, 2950-2959. doi: 10.1093/eurheartj/ehu299

Niemann, B., Chen, Y., Issa, H., Silber, R.-E., and Rohrbach, S. (2010). Caloric restriction delays cardiac ageing in rats: role of mitochondria. Cardiovasc. Res. 88, 267-276. doi: 10.1093/cvr/cvq273

Noyan, H., El-Mounayri, O., Isserlin, R., Arab, S., Momen, A., Cheng, H. S., et al. (2015). Cardioprotective signature of short-term caloric restriction. PLoS ONE 10:e0130658. doi: 10.1371/journal.pone.0130658

Ohkawa, H., Ohishi, N., and Yagi, K. (1979). Assay for lipid peroxides in animal tissues by thiobarbituric acid reaction. Anal. Biochem. 95, 351-358. doi: 10.1016/0003-2697(79)90738-3

Okoshi, M. P., Okoshi, K., Pai, V. D., Pai-Silva, M. D., Matsubara, L. S., and Cicogna, A. C. (2001). Mechanical, biochemical, and morphological changes in the heart from chronic food-restricted rats. Can. J. Physiol. Pharmacol. 79, 754-760. doi: 10.1139/y01-060

Park, S. Y., Choi, G. H., Choi, H. I., Ryu, J., Jung, C. Y., and Lee, W. (2005). Calorie restriction improves whole-body glucose disposal and insulin resistance in association with the increased adipocyte-specific GLUT4 expression in Otsuka Long-Evans Tokushima Fatty rats. Arch. Biochem. Biophys. 436, 276-284. doi: 10.1016/j.abb.2005.01.010

Peart, J. N., See Hoe, L., Pepe, S., Johnson, P., and Headrick, J. P. (2012). Opposing effects of age and calorie restriction on molecular determinants of myocardial ischemic tolerance. Rejuvenation Res. 15, 59-70. doi: 10.1089/rej.2011.1226

Peron, A. P., Saraiva, R. M., Antonio, E. L., Andriolo, A., and Tucci, P. J. F. (2005). Food restriction does not impair myocardial mechanics during the healing period of myocardial infarction in the rat. Nutr. Res. 25, 1075-1084. doi: 10.1016/j.nutres.2005.10.003

Powers, S. K., Quindry, J. C., and Kavazis, A. N. (2008). Exercise-induced cardioprotection against myocardial ischemia-reperfusion injury. Free Radic. Biol. Med. 44, 193-201. doi: 10.1016/j.freeradbiomed.2007.02.006

Schutte, R., Thijs, L., Asayama, K., Boggia, J., Li, Y., Hansen, T., et al. (2013). Double product reflects the predictive power of systolic pressure in the general population: evidence from 9937 participants. Am. J. Hypertens. 26, 665-672. doi: 10.1093/ajh/hps119

Shinmura, K., Tamaki, K., Sano, M., Murata, M., Yamakawa, H., Ishida, H., et al. (2011). Impact of long-term caloric restriction on cardiac senescence: caloric restriction ameliorates cardiac diastolic dysfunction associated with aging. J. Mol. Cell. Cardiol. 50, 117-127. doi: 10.1016/j.yjmcc.2010.10.018

Silachev, D. N., Plotnikov, E. Y., Pevzner, I. B., Zorova, L. D., Babenko, V. A., Zorov, S. D., et al. (2014). The Mitochondrion as a key regulator of ischaemic tolerance and injury. Heart Lung Circ. 23, 897-904. doi: 10.1016/j.hlc.2014.05.022

Sugizaki, M. M., Leopoldo, A. S., Okoshi, M. P., Bruno, A., Conde, S. J., LimaLeopoldo, A. P., et al. (2009). Severe food restriction induces myocardial dysfunction related to SERCA2 activity. Can. J. Physiol. Pharmacol. 87, 666-673. doi: 10.1139/Y09-060

Suzuki, K., Murtuza, B., Sammut, I. A., Latif, N., Jayakumar, J., Smolenski, R. T., et al. (2002). Heat shock protein 72 enhances manganese superoxide dismutase activity during myocardial ischemia-reperfusion injury, associated with mitochondrial protection and apoptosis reduction. Circulation 106, 270-276. doi: 10.1161/01.cir.0000032880.55215.92

Nwagha, U., Ikekpeazu, E., Ejezie, F., Neboh, E., and Maduka, I. (2010). Atherogenic index of plasma as useful predictor of cardiovascular risk among postmenopausal women in Enugu, Nigeria. Afr. Health Sci. 10, 248-252.

Walsh, M. E., Shi, Y., and Van Remmen, H. (2014). The effects of dietary restriction on oxidative stress in rodents. Free Radic. Biol. Med. 66, 88-99. doi: 10.1016/j.freeradbiomed.2013.05.037

Yamagishi, T., Bessho, M., Yanagida, S., Nishizawa, K., Kusuhara, M., Ohsuzu, F., et al. (2010). Severe, short-term food restriction improves cardiac function following ischemia/reperfusion in perfused rat hearts. Heart Vessels 25, 417-425. doi: 10.1007/s00380-009-1222-6 
Young, D. B. (2010). Control of Cardiac Output. San Rafael, CA: Morgan \& Claypool Life Sciences. Available online at: http://www.ncbi.nlm.nih.gov/ books/NBK54469/

Conflict of Interest Statement: The authors declare that the research was conducted in the absence of any commercial or financial relationships that could be construed as a potential conflict of interest.
Copyright (C) 2016 Melo, Costa-Pereira, Santos, Mendes, Costa, Santos, Rocha-Vieira, Magalhães, Esteves, Ferreira, Guatimosim and Dias-Peixoto. This is an open-access article distributed under the terms of the Creative Commons Attribution License (CC $B Y)$. The use, distribution or reproduction in other forums is permitted, provided the original author(s) or licensor are credited and that the original publication in this journal is cited, in accordance with accepted academic practice. No use, distribution or reproduction is permitted which does not comply with these terms. 